Tohoku J. Exp. Med., 2007, 212, 341-348

\title{
The Mechanism of Suicide-Inactivation of Tyrosinase: A Substrate Structure Investigation
}

\author{
Edward J. Land, ${ }^{1}$ Christopher A. Ramsden ${ }^{1}$ and Patrick A. Riley ${ }^{2}$ \\ ${ }^{1}$ Lennard-Jones Laboratories, School of Physical and Geographical Sciences, Keele University, \\ Staffordshire, U.K. \\ ${ }^{2}$ Totteridge Institute for Advanced Studies, London, U.K.
}

LAND, E.J., RAmSDEn, C.A. and Riley, P.A. The Mechanism of Suicide-Inactivation of Tyrosinase: A Substrate Structure Investigation. Tohoku J. Exp. Med., 2007, 212 (4), 341-348 - Tyrosinase is a copper-containing mono-oxygenase, widely distributed in nature, able to catalyze the oxidation of both phenols and catechols to the corresponding ortho-quinones. Tyrosinase is characterised by a hitherto unexplained irreversible inactivation which occurs during the oxidation of catechols. Although the corresponding catechols are formed during tyrosinase oxidation of monophenols, inactivation in the presence of monophenolic substrates is minimal. Previous studies have established the kinetic features of the inactivation reaction which is first-order in respect of the enzyme concentration. The inactivation reaction exhibits the same $\mathrm{pH}$-profile and saturation properties as the oxidation reaction, classing the process as a mechanism-based suicide inactivation. The recent elucidation of the crystallographic structure of tyrosinase has stimulated a new approach to this long-standing enigma. Here we report the results of an investigation of the tyrosinase-catalysed oxidation of a range of hydroxybenzenes which establish the structural requirements associated with inactivation. We present evidence for an inactivation mechanism based on catechol hydroxylation, with loss of one of the copper atoms at the active site. The inactivation mechanism involves two linked processes occurring in situ: (a) catechol presentation resulting in $\alpha$-oxidation, and (b) deprotonation of an adjacent group. On the basis of our experimental data we believe that a similar mechanism may account for the inhibitory action of resorcinols. — tyrosinase; suicideinactivation; catecholase; cresolase; $\alpha$-oxidation; deprotonation

(C) 2007 Tohoku University Medical Press

When catechols are oxidised by tyrosinase there is a consistent anomaly in the oxygen stoichiometry. This phenomenon is amplified as the enzyme concentration is reduced. At low enzyme concentration the reaction ceases before either the substrate or the oxygen are depleted and further substrate supplementation or re-oxygenation have no effect. However, further enzyme addition re-initiates the reaction and the extent of further oxidation is a linear function of the amount of enzyme added. The effect is not due to a nonspecific influence of protein addition and re-initiation of oxidation is not observed when heat-inactivated tyrosinase is added to the reaction mixture. It is clear, therefore, that, during the oxidation of the substrate, a process occurs that

Received May 2, 2007; revision accepted for publication May 30, 2007.

Correspondence: Prof. P.A. Riley, Totteridge Institute for Advanced Studies, The Grange, Grange Avenue, London N20 8AB, U.K. e-mail: rebc900@ucl.ac.uk 
inactivates tyrosinase. This phenomenon, often referred to as "suicide inactivation", is a characteristic of several enzymes (Walsh 1984) and has long been recognised as a feature of both plant and animal tyrosinases (Nelson and Dawson 1944).

The biological significance of the reactioninactivation may be as a limitation of the activity of an enzyme generating potentially cytotoxic oxidation products. It has been the subject of many studies (Asimov and Dawson 1950; Ingraham et al. 1952; Tomita and Seiji 1977; Seiji et al. 1978; Tomita et al. 1980; Lerch 1983; Miranda and Botti 1983; Waley 1985; GarciaCanovas et al. 1987; Tudela et al. 1988; Haghbeen et al. 2004; Garcia-Molina et al. 2005), but the details of the mechanism of the inactivation have remained unclear.

Two general mechanistic proposals to account for the inactivation have been advanced: (1) an attack by the ortho-quinone product of oxidation on a sensitive nucleophilic group vicinal to the active site (Ingraham et al. 1952), and (2) a free radical attack on the active site by reactive oxygen species generated during the catalytic oxidation (Seiji et al. 1978). However, experiments in which ortho-quinone binding was prevented failed to influence inactivation and attempts to protect the enzyme with radical scavengers proved unsuccessful (Tomita et al. 1980; Dietler and Lerch 1982).

In this study we examined the reaction-inactivation of mushroom tyrosinase using a range of substrates and have examined both the kinetics of the process and structural aspects of the substrate specificity. From these data we have derived a plausible mechanism of suicide inactivation. A kinetic model of catechol metabolism by competing alternative pathways, one yielding the normal ortho-quinone oxidation product and the other generating a product that inactivates the enzyme, closely simulates the kinetic features of the phenomenon and exhibits a near-linear relationship between the extent of oxidation and the amount of added enzyme, as found experimentally. In this paper we propose that the inactivation mechanism involves a presentation at the active site of the catechol substrate as a cresol, i.e. a "cresolase" presentation as opposed to a "catecholase" presentation (Mason 1955). This leads to the catechol being oxidised to form a product able to undergo deprotonation and reductive elimination of an ortho-quinone which results in inactivation of the enzyme by formation of copper(0) at the active site. A similar mechanism may account for the inhibitory properties of resorcinols.

\section{Materials ANd Methods}

\section{Chemicals}

The reagents used in this study were purchased from Sigma-Aldrich, Poole, Dorset, UK. Tyrosinase (from Agaricus bisporus) was made up at a concentration of 300 (Sigma) units per $\mathrm{ml}$ in $0.1 \mathrm{M}$ phosphate buffer $(\mathrm{pH}$ 7.4), frozen in aliquots of $5 \mathrm{ml}$, and stored at $-20^{\circ} \mathrm{C}$. Solutions of substrates were freshly prepared in glass distilled water. The agents tested included a range of potential tyrosinase substrates shown in Table 1. The following compounds were not commercially available and were prepared by the literature methods cited: 4,6-dimethylresorcinol (Cram and Cranz 1950); 4-fluorocatechol (Corse and Ingraham 1951); (3-hydroxyphenyl) acetonitrile (Salkowski 1884). 4-Methoxycatechol was prepared by Mr. C.J. Cooksey (University College London) and 3,6-dimethylcatechol was provided by Professor Marco d'Ischia (University of Naples).

\section{Oximetry}

Experiments were conducted at $30^{\circ} \mathrm{C}$ using an apparatus consisting of a quartz cuvette $(3.65 \mathrm{mls}$ capacity) adapted to hold a Clark-type oxygen electrode, as described previously (Cooksey et al. 1997). Spectrophotometric data were recorded using a HewlettPackard diode-array spectrophotometer (Model 8452A) and the oxygen uptake monitored using a Yellow Springs Instruments (Model 5300) polarimeter. Oxygen electrode tracings were converted to electronic form using ScanIt software (Version 1.0, J. van Baten and R. Baur 2002). Kinetic analysis was conducted using the Origin 61 program (OriginLab Co., Northampton, MA, USA). Simulations were performed using an in-house computer model. Spectral changes were examined using the kinetic mode of the UV-Vis Chemstation A0801(66) software (Agilent Technologies, Hannover, Germany). Unless otherwise stated the assays were performed at $\mathrm{pH} 6.75$ with a substrate concentration of $820 \mu \mathrm{M}$ and enzyme concentrations between 1-10 units $/ \mathrm{ml}$. The total oxygen 
utilization was found to fit the equation:

$$
U_{t}=\frac{k_{1}}{k_{2}} E_{0}\left(1-\exp \left[-k_{2} t\right]\right)
$$

where $U_{\mathrm{t}}=$ oxygen utilised at time $\mathrm{t} ; E_{0}=$ initial amount of enzyme; $k_{1}=$ oxidation rate; $k_{2}=$ inactivation rate of the enzyme. From the total oxygen utilized $\left(U_{\mathrm{T}}\right)$ the oxidation rate was derived as: $k_{1}=U_{\mathrm{T}} \cdot k_{2} / E_{0}$. The standard test substrate was 4-methylcatechol which exhibits a linear relationship between the total oxygen utilization and the amount of enzyme $\left(U_{T}=24.1\right.$ nanomoles oxygen per unit, $\left.\mathrm{r}^{2}=0.9577\right)$. To test for residual catecholase activity $\left(\mathrm{RA}_{\text {cat }}\right.$ in Table 1) 4-methylcatechol was added at the end of the oxygen uptake or after 5 minutes if no oxygen uptake was observed and the secondary oxygen utilization measured and expressed as a percentage of the control value. 4-Methylphenol was used as competitive cresolase substrate and for the estimation of residual cresolase activity $\left(\mathrm{RA}_{\mathrm{cr}}\right.$ in Table 1$)$.

\section{Results ANd Discussion}

The structure-activity comparison is summarized in Table 1.

The data divide the compounds tested into four categories: (1) compounds that are oxidised by tyrosinase as demonstrated by oxygen utilization and which lead to inactivation (entries 1-9); (2) compounds that are oxidised but are not inactivating (entries 10-13); (3) compounds that show no oxygen uptake and are not associated with any detectable loss of activity (entries 14-21); and (4) compounds that show no oxygen uptake but are associated with loss of residual activity against the standard 4-methylcatechol substrate (entries 22-25).

Catechols, with the exception of 3,6-dimethylcatechol (entry 19) and 4-nitrocatechol (entry 18), are substrates for tyrosinase and exhibit oxygen uptake, although in position 3 an alkyl group greatly hinders the oxidation rate (entries 10 \& 11) and fluoride (entry 8) diminishes the relative inactivation rate. Substitution in the 4-position alters the oxidation $\left(k_{l}\right)$ and the inactivation $\left(k_{2}\right)$ rates to differing extents. For example, the nitro function (entry 18) prevents oxidation by tyrosinase whilst fluoride (entry 2) decreases the rela- tive inactivation rate. The ratio $k_{2} / k_{1}$ represents the proportion of inactivating to catalytic reactions and this varies between 1.4 and $10 \%$ for the compounds tested. Inactivation was confirmed by zero residual activity (RA in Table 1) of the enzyme after cessation of oxygen uptake. Residual activity was tested both for catecholase $\left(\mathrm{RA}_{\text {cat }}\right)$ and cresolase $\left(\mathrm{RA}_{\mathrm{cr}}\right)$ using 4-methylcatechol and 4-methylphenol as substrates respectively.

Of the benzenetriols, 1,3,5-benzenetriol (entry 15) was neither a primary substrate nor an inactivator. 1,2,4-Benzenetriol (entry 12) was shown to be a substrate for tyrosinase and seemed to possess little inactivating activity, but the experiments had to be performed at $\mathrm{pH} 3.5$ (indicated by note [a] in Table 1) to halt the rapid autoxidation of this compound, so direct comparison with the data from other compounds is not possible. Pyrogallol (1,2,3-benzenetriol) (entry 13) was a primary substrate and exhibited no inactivating effect.

Hydroquinone (entry 14) and 3-ethylhydroquinone (entry 21) were neither primary substrates nor inactivators but hydroquinone was found to be oxidised indirectly by redox exchange with 4-methyl-ortho-quinone in the test for residual catecholase activity $\left(\mathrm{RA}_{\text {cat }}\right)$ of the enzyme (indicated by note [b] in Table 1). This phenomenon was also observed with some other compounds that were not directly oxidised by tyrosinase, notably 1,3,5-benzenetriol (entry 15). The anomalous additional oxygen utilization found in the RA test may have been due to the generation of competitive substrates.

Resorcinols (entries 22,23,25) were not primary substrates and failed to show oxygen utilization. However, inactivating activity was demonstrated by the marked reduction of residual enzyme activity in the case of 4,6-dimethylresorcinol (entry 22), resorcinol (entry 23) and 4-ethylresorcinol (entry 25). This effect was also evident with (3-hydroxyphenyl) acetonitrile (entry 24) but not 3-methoxyphenol (entry 20). 2-Methyl- and 2,5-dimethylresorcinol (entries 16,17) were neither substrates nor inactivators.

The minimum set of conditions consistent 
TABLE 1. Tyrosinase oximetry results.<smiles>[R]Cc1c([R])c([R])c([R])c([R])c1O</smiles>

\begin{tabular}{|c|c|c|c|c|c|c|c|c|c|c|c|}
\hline No. & Compound & $\mathrm{R}^{2}$ & $\mathrm{R}^{3}$ & $\mathrm{R}^{4}$ & $\mathrm{R}^{5}$ & $\mathrm{R}^{6}$ & oxy & $k_{1}$ & $k_{2}$ & $\mathrm{RA}_{\text {cr }}$ & $\mathrm{RA}_{\text {cat }}$ \\
\hline 1 & 4-ethylcatechol & $\mathrm{OH}$ & $\mathrm{H}$ & $\mathrm{C}_{2} \mathrm{H}_{5}$ & $\mathrm{H}$ & $\mathrm{H}$ & yes & 33.5 & 3.50 & 0 & 0 \\
\hline 2 & 4-fluorocatechol & $\mathrm{OH}$ & $\mathrm{H}$ & $\mathrm{F}$ & $\mathrm{H}$ & $\mathrm{H}$ & yes & 66.5 & 3.30 & 0 & 0 \\
\hline 3 & 4-methylcatechol & $\mathrm{OH}$ & $\mathrm{H}$ & $\mathrm{CH}_{3}$ & $\mathrm{H}$ & $\mathrm{H}$ & yes & 74.1 & 3.26 & 0 & 0 \\
\hline 4 & 4-methoxycatechol & $\mathrm{OH}$ & $\mathrm{H}$ & $\mathrm{OCH}_{3}$ & $\mathrm{H}$ & $\mathrm{H}$ & yes & 19.9 & 1.86 & 0 & 0 \\
\hline 5 & catechol & $\mathrm{OH}$ & $\mathrm{H}$ & $\mathrm{H}$ & $\mathrm{H}$ & $\mathrm{H}$ & yes & 65.4 & 0.95 & 0 & 0 \\
\hline 6 & 4-n-propylcatechol & $\mathrm{OH}$ & $\mathrm{H}$ & $\mathrm{C}_{3} \mathrm{H}_{7}$ & $\mathrm{H}$ & $\mathrm{H}$ & yes & 23.0 & 0.86 & 0 & 0 \\
\hline 7 & 4-chlorocatechol & $\mathrm{OH}$ & $\mathrm{H}$ & $\mathrm{Cl}$ & $\mathrm{H}$ & $\mathrm{H}$ & yes & 21.3 & 0.71 & 0 & 0 \\
\hline 8 & 3-fluorocatechol & $\mathrm{OH}$ & $\mathrm{F}$ & $\mathrm{H}$ & $\mathrm{H}$ & $\mathrm{H}$ & yes & 25.6 & 0.35 & 0 & 0 \\
\hline 9 & 3,5-dimethylcatechol & $\mathrm{OH}$ & $\mathrm{H}$ & $\mathrm{CH}_{3}$ & $\mathrm{H}$ & $\mathrm{CH}_{3}$ & yes & 4.35 & 0.19 & nd & nd \\
\hline 10 & 3-methylcatechol & $\mathrm{OH}$ & $\mathrm{CH}_{3}$ & $\mathrm{H}$ & $\mathrm{H}$ & $\mathrm{H}$ & yes & 1.1 & 0.03 & nd & nd \\
\hline 11 & 3-ethylcatechol & $\mathrm{OH}$ & $\mathrm{C}_{2} \mathrm{H}_{5}$ & $\mathrm{H}$ & $\mathrm{H}$ & $\mathrm{H}$ & yes & 0.5 & 0.02 & nd & nd \\
\hline 12 & 1,2,4-benzenetriol (a) & $\mathrm{OH}$ & $\mathrm{H}$ & $\mathrm{OH}$ & $\mathrm{H}$ & $\mathrm{H}$ & yes & 8.4 & 0.02 & nd & nd \\
\hline 13 & pyrogallol & $\mathrm{OH}$ & $\mathrm{OH}$ & $\mathrm{H}$ & $\mathrm{H}$ & $\mathrm{H}$ & yes & 31.6 & $<0.01$ & nd & 104 \\
\hline 14 & hydroquinone (b) & $\mathrm{H}$ & $\mathrm{H}$ & $\mathrm{OH}$ & $\mathrm{H}$ & $\mathrm{H}$ & no & 0.0 & - & + & 281 \\
\hline 15 & 1,3,5-benzenetriol (b) & $\mathrm{H}$ & $\mathrm{OH}$ & $\mathrm{H}$ & $\mathrm{OH}$ & $\mathrm{H}$ & no & 0.0 & - & + & 156 \\
\hline 16 & 2,5-dimethylresorcinol & $\mathrm{CH}_{3}$ & $\mathrm{OH}$ & $\mathrm{H}$ & $\mathrm{CH}_{3}$ & $\mathrm{H}$ & no & 0.0 & - & + & 112 \\
\hline 17 & 2-methylresorcinol & $\mathrm{CH}_{3}$ & $\mathrm{OH}$ & $\mathrm{H}$ & $\mathrm{H}^{3}$ & $\mathrm{H}$ & no & 0.0 & - & + & 107 \\
\hline 18 & 4-nitrocatechol & $\mathrm{OH}$ & $\mathrm{H}$ & $\mathrm{NO}_{2}$ & $\mathrm{H}$ & $\mathrm{H}$ & no & 0.0 & - & + & 104 \\
\hline 19 & 3,6-dimethylcatechol & $\mathrm{OH}$ & $\mathrm{CH}_{3}$ & $\mathrm{H}^{2}$ & $\mathrm{H}$ & $\mathrm{CH}_{3}$ & no & 0.0 & - & + & 102 \\
\hline 20 & 3-methoxyphenol & $\mathrm{H}$ & $\mathrm{OCH}_{3}$ & $\mathrm{H}$ & $\mathrm{H}$ & $\mathrm{H}$ & no & 0.0 & - & + & 100 \\
\hline 21 & 3-ethylhydroquinone & $\mathrm{H}$ & $\mathrm{C}_{2} \mathrm{H}_{5}$ & $\mathrm{OH}$ & $\mathrm{H}$ & $\mathrm{H}$ & no & 0.0 & - & + & 73 \\
\hline 22 & 4,6-dimethylresorcinol & $\mathrm{H}$ & $\mathrm{OH}$ & $\mathrm{CH}_{3}$ & $\mathrm{H}$ & $\mathrm{CH}_{3}$ & no & 0.0 & - & 0 & 52 \\
\hline 23 & resorcinol & $\mathrm{H}$ & $\mathrm{OH}$ & $\mathrm{H}$ & $\mathrm{H}$ & $\mathrm{H}$ & no & 0.0 & - & 0 & 27 \\
\hline 24 & (3-hydroxyphenyl)acetonitrile & $\mathrm{H}$ & $\mathrm{CH}_{2} \mathrm{CN}$ & $\mathrm{H}$ & $\mathrm{H}$ & $\mathrm{H}$ & no & 0.0 & - & 0 & 17 \\
\hline 25 & 4-ethylresorcinol & $\mathrm{H}$ & $\mathrm{OH}$ & $\mathrm{C}_{2} \mathrm{H}_{5}$ & $\mathrm{H}$ & $\mathrm{H}$ & no & 0.0 & - & 0 & 13 \\
\hline
\end{tabular}

The general structure of the substrates investigated is illustrated with variations in the substituents at various positions on the ring indicated in the Table. Four general categories of substrates are indicated: (a) Compounds oxidised and exhibiting inactivation kinetics (entries 1-9); (b) compounds oxidised but which fail to exhibit inactivation kinetics (entries 10-13); (c) compounds that show no oxygen utilization and no inactivation (entries 14-21); and (d) compounds that show no oxygen utilization but possess inactivation properties (entries 22-25). The column labelled "oxy" indicates observable oxygen utilization in the presence of tyrosinase. The calculated oxidation $\left(k_{l}\right)$ and inactivation $\left(k_{2}\right)$ rates permit the estimation of the proportion of reactions leading to inactivation. Following exposure to each compound the residual cresolase and catecholase activities of the enzyme are shown as $\mathrm{RA}_{\mathrm{cr}}$ and $\mathrm{RA}_{\text {cat }}$.

In the case of entries 9-13 it was not possible to carry out the RA tests (indicated as "nd") as there was no end-point to the prior oxidation reaction. In the case of entry 12 the oxidation experiments were conducted at $\mathrm{pH} 3.5$ (indicated by [a] in the Table). In the case of entries 14 and 15 (indicated [b] in the Table) there was spectrophotometric evidence of the generation of secondary products by redox exchange, possibly forming competitive substrates. 
with these data may be stated as follows:

1. Substrate binding is to one of the active site copper atoms through a hydroxyl group in position 1.

2. "Catecholase" substrate binding to the active site involves a hydroxyl group in position 2 binding to the second active site copper atom.

3. In "cresolase" substrate binding the oxygen insertion to the ring is in position 2 .

4. Substrate binding is prevented by a hydroxyl group in position 4 .

5. "Cresolase" substrate binding is excluded by a hydroxyl group at position 5 .

On this basis the mechanism that we now propose is that the inactivation of tyrosinase during catechol oxidation is due to the catechol being capable of an alternative "cresolase" presentation (Scheme 1). The recent crystallographic determination of the structure of the dinuclear copper active centre of Streptomyces tyrosinase (Matoba et al. 2006) permits the assignment of the likely orientation of substrate binding. The normal cresolase presentation of phenols assumes that the orientation of the phenyl ring in the enzymesubstrate complex is approximately orthogonal to the plane defined by the copper and oxygen atoms (Decker et al. 2006), as proposed by Canters and co-workers (Van Gastel et al. 2000; Bubacco et al. 2003). This differs in orientation significantly from the assumed catecholase configuration in<smiles>NC1(N)O[Si](N)(N)O1</smiles>

oxy-tyrosinase
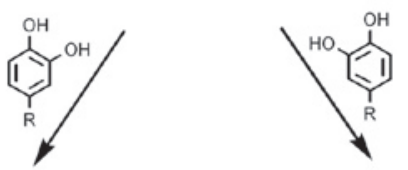

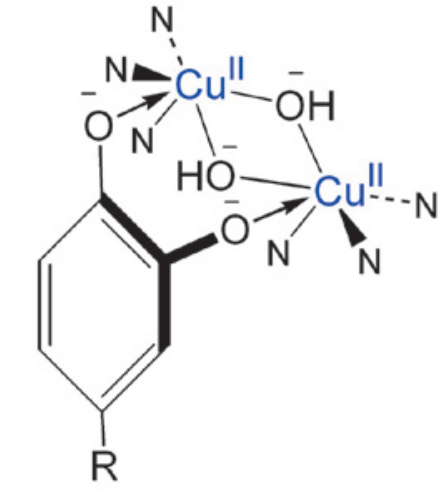

'catecholase' presentation

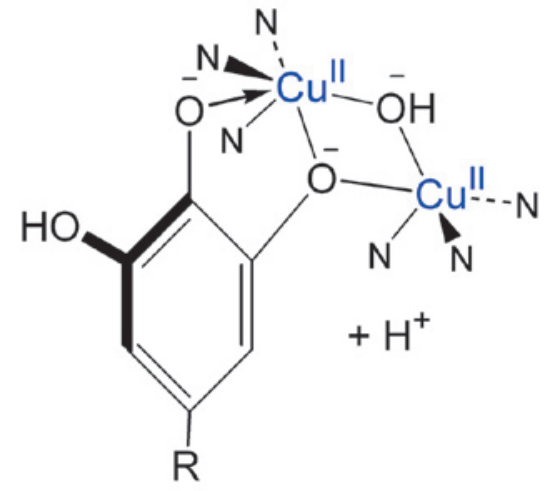

'cresolase' presentation

Scheme 1. Alternative presentations of catechols to oxy-tyrosinase.

The normal binding of catechols to oxy-tyrosinase ("catecholase" presentation) is indicated on the left; whereas the alternative "cresolase" presentation (shown on the right) is the normal mode of binding of phenols to $o x y$-tyrosinase. 
which the binding of the adjacent hydroxyl groups requires the phenyl ring to be oriented approximately in the same plane as the active site copper and oxygen atoms.

Oxygen addition to the catechol ring by cresolase activity generates an intermediate product which can undergo deprotonation and reductive elimination as shown by the curly arrows in Scheme 2. We propose that this in situ deprotonation leads to the inactivation of the enzyme by formation of $\mathrm{Cu}(0)$, which does not bind to the histidine ligands. This is consistent with the experimental observation that $50 \%$ of the copper is lost from the active site during catechol inactivation (Dietler and Lerch 1982).

According to the model outlined above the progressive enzyme inactivation observed during catechol oxidation is therefore the result of a proportion of the substrate being processed by the cresolase route. The rate of this process involves a combination of the relative likelihood of the alternative modes of substrate binding and the rate of deprotonation.

In the light of the proposed cresolase action of tyrosinase on catechols it seems likely that the inhibitory action of 1,3-dihydroxybenzene derivatives (resorcinols) might also come about through a similar mechanism (Scheme 2).

Some of the differences in the observed structural effects on the inactivation reaction (Table 1) may be attributable to substituent influences on the rate of deprotonation. Slowly deprotonating oxidation products may be released as the $\alpha$-hydroxyquinone and, by redox exchange
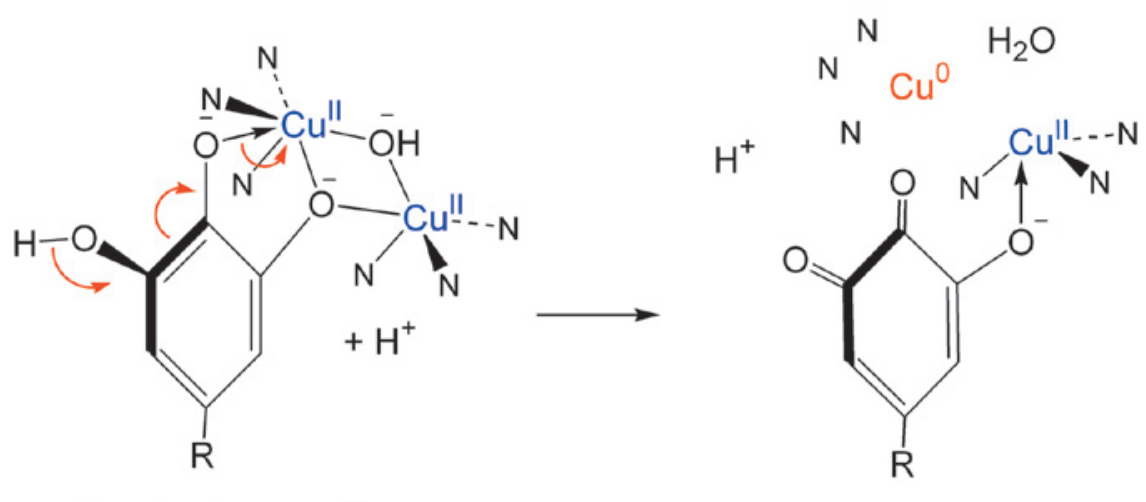

'cresolase' presentation of catechols

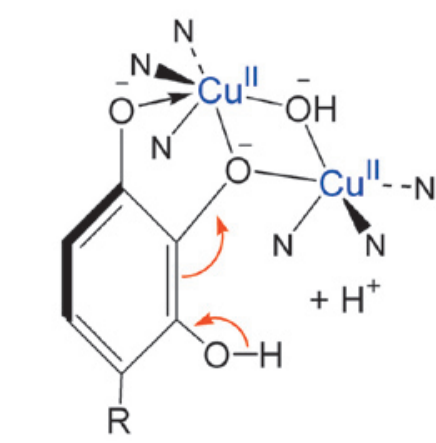

'cresolase' presentation of resorcinols<smiles>[2H]C1CC(CC(C)C)OC1=O</smiles>

$\mathrm{N}$

$\mathrm{N}$

N<smiles>NC(N)[C@@H](N)O</smiles>

inactivated tyrosinase

Scheme 2. Deprotonation and reductive elimination of "cresolase"-bound catechols or resorcinols.

The curly arrows show the effect of deprotonation leading to the reduction of copper $(\mathrm{Cu}(\mathrm{II}) \rightarrow$ $\mathrm{Cu}(0)$ ), elimination of an ortho-quinone and inactivation of tyrosinase. 
with a catecholic substrate, yield the 1,2,3-trihydroxy products. There is evidence in the literature of enzymatic 5-hydroxylation of L-dopa (Hansson et al. 1980, 1981; Agrup et al. 1982; Carlberg et al. 1984; Burzio and Waite 2002) which appears to confirm the ability of tyrosinase to oxidise catechols by the cresolase route. Significant evidence favouring our proposed mechanism is the failure of pyrogallol (1,2,3-trihydroxybenzene) to exhibit inactivation kinetics since, owing to the active site constraints 4 and 5 outlined above, this substrate, due to the three adjacent hydroxy groups, is unable to present in the requisite cresolase orientation. This is also consistent with the ability of 4-methylphenol (a primary cresolic substrate) to act as an inhibitor of the inactivation reaction by competition for cresolase binding by the catechol (Fig. 1).

The deprotonation step envisaged in Scheme 2 is supported by the data showing that inactivation takes place in the presence of (3-hydroxyphenyl) acetonitrile (entry 24, Table 1), which is capable of deprotonation, but not with 3-methoxyphenol (entry 20), which is not.

Because our proposed inactivation mecha-

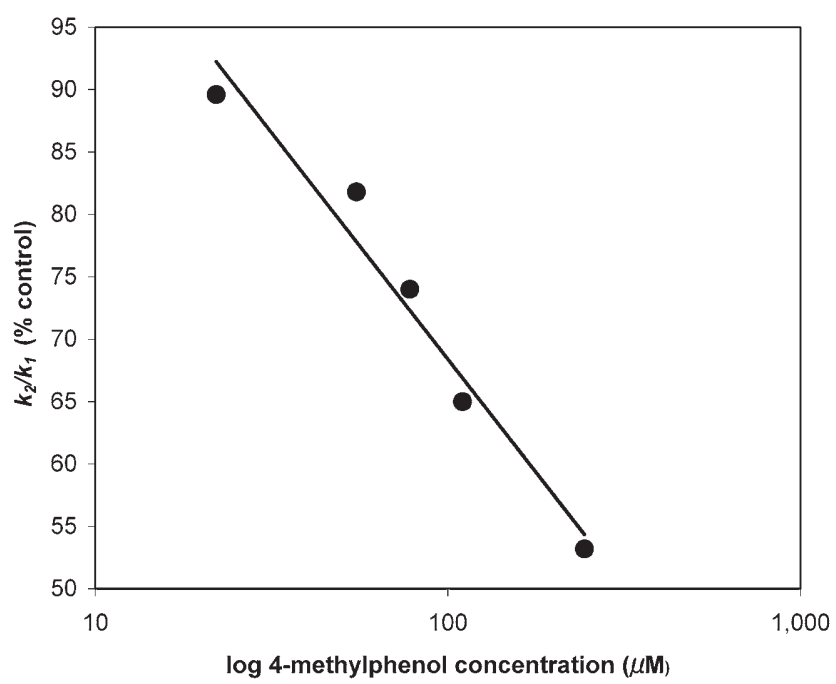

Fig. 1. Effect of 4-methylphenol on the kinetics of 4-methylcatechol oxidation.

Semi-logarithmic plot of the reduction in the proportional inactivation rate $\left(k_{2} / k_{l}\right)$ of tyrosinase by 4 -methylcatechol with increasing concentration of 4-methylphenol. nism involves oxygen insertion into the phenyl ring, inactivation is restricted to $o x y$-tyrosinase. During catechol oxidation this form of the enzyme is regenerated from met-tyrosinase (Lerch 1983) so that all of the initial enzyme is eventually inactivated, as observed. The proposed inactivation mechanism is entirely consistent with the data we have presented relating to tyrosinase from Agaricus bisporus. Further investigations will be required to demonstrate that it is a satisfactory general explanation of tyrosinase suicide inactivation but, in view of the strongly conserved structure of the active site (Spritz et al. 1997), we believe that it is likely that a similar mechanism is responsible for the observations in all tyrosinases. If, as we propose, suicide inactivation of tyrosinase depends on anomalous catechol oxidation, the slow accumulation of catechols by the indirect generation in the predominantly cresolase system involved in mammalian pigmentation would account for the delayed inactivation of tyrosinase in melanosomes (Seiji et al. 1978; Tomita et al. 1980).

In view of the involvement of a deprotonation as part of the proposed inactivation mechanism it would be anticipated that the relative rate of inactivation $\left(k_{2} / k_{1}\right)$ will be influenced by the proton concentration. Preliminary experiments conducted with 4-methylcatechol indicate that this is indeed the case, with a reduction in relative inactivation at lower $\mathrm{pH}\left(\delta\left[k_{2} / k_{1}\right]=6.7 \times 10^{-2}\right.$ per $\mathrm{pH}$ unit; $\left.\mathrm{r}^{2}=0.9194\right)$. We plan to examine this aspect further in a subsequent publication.

In our proposed mechanism the enzyme inactivation is the consequence of the formation of zero-valency copper. We are not aware of other examples although, in principle, metal detachment from coordinating ligands might be anticipated as a route of metallo-enzyme inactivation. Attempts to reactivate the inactivated tyrosinase by $\mathrm{Cu}$ (II) addition were unsuccessful which may indicate the requirement for a "caddie" protein (Matoba et al. 2006), or that further damage to the metal-binding site of the enzyme is involved. It is possible that dioxygen may bind to the remaining copper atom of the inactivated tyrosinase leading, via a radical mechanism, to histidine damage, as 
described by Dietler and Lerch (1982).

\section{Acknowledgments}

We thank Professor Marco d'Ischia and Dr. Alessandro Pezzella (University of Naples) for making available 3,6-dimethylcatechol. We are grateful to John Clews (Keele University) and Christopher Cooksey (University College London) for synthesizing other compounds tested. PAR thanks Dr. Konrad Lerch for helpful comments and Professor Peter Wardman for the provision of laboratory facilities at the Gray Cancer Institute. We are grateful to Unilever R \& D for financial support.

\section{References}

Agrup, G., Rorsman, H. \& Rosengren, E. (1982) 5-OH-dopa, product of and substrate for tyrosinase. Acta Dermatovener. (Stockholm), 62, 371-376.

Asimov, I. \& Dawson, C.R. (1950) On the reaction inactivation of tyrosinase during aerobic oxidation of catechol. J. Biol. Chem., 72, 820-828.

Bubacco, L., van Gastel, M., Groenen, E.J.J., Vijgenboom, E. \& Canters, G.W. (2003) Spectroscopic characterization of the electronic changes in the active site of Streptomyces antibioticus tyrosinase upon binding of transition state analogue inhibitors. J. Biol. Chem., 278, 7381-7389.

Burzio, L.A. \& Waite, J.H. (2002) The other topa: formation of 3,4,5-trihydroxyphenylalanine in peptides. Analyt. Biochem., 306, 108-114.

Carlberg, M., Jergil, B., Lindbladh, C. \& Rosengren, E. (1984) Enzymatic 5-hydroxylation of L-dopa by a tyrosinase isolated from the sea anemone Metrium senile. Gen. Pharmacol., 15, 301-307.

Cooksey, C.J., Garratt, P.J., Land, E.J., Pavel, S., Ramsden, C.A., Riley, P.A. \& Smit, N.P.M. (1997) Evidence of the indirect formation of the catecholic intermediate substrate responsible for the autoactivation kinetics of tyrosinase. J. Biol. Chem., 272, 26226-26235.

Corse, J. \& Ingraham, L.L. (1951) The monofluorocatechols. J. Org. Chem., 16, 1345-1348.

Cram, D.J. \& Cranz, F.W. (1950) Mold Metabolite. IV. The ultraviolet absorption spectra of certain aromatic hydroxyketones. J. Am. Chem. Soc., 72, 595-600.

Decker, H., Schweikardt, T. \& Tuczek, F. (2006) The first crystal structure of tyrosinase: All questions answered? Angew. Chem. Int. Ed., 45, 4546-4550.

Dietler, C. \& Lerch, K. (1982) Reaction inactivation of tyrosinase. In: Oxidases and Related Redox Systems, edited by T.E. King, H.S. Mason \& M. Morrison, Pergamon Press, NY, pp. 305-317.

Garcia-Canovas, F., Tudela, J., Martinez-Madrid, C., Varon, R., Garcia-Carmona, F. \& Lozano, J.A. (1987) Kinetic study on the suicide inactivation of tyrosinase induced by catechol. Biochim. Biophys. Acta, 912, 417-423.

Garcia-Molina, F., Hiner, A.N., Fenoll, L.G., Rodriguez-Lopez, J.N., Garcia-Ruiz, P.A., Garcia-Canovas, F. \& Tudela, J. (2005) Mushroom tyrosinase: catalase activity, inhibition, and suicide inactivation. J. Agric. Food Chem., 53,
3702-3709.

Haghbeen, K., Saboury, A.A. \& Karbassi, F. (2004) Substrate share in the suicide inactivation of mushroom tyrosinase. Biochim. Biophys. Acta, 1675, 139-146.

Hansson, C., Rorsman, H. \& Rosengren, E. (1980) 5-Hydroxydopa, a new compound in the Raper-Mason scheme of melanogenesis. Acta Dermatovener. (Stockholm), 60, 281-186.

Hansson, C., Rorsman, H. \& Rosengren, E. (1981) Pronounced formation of 5-OH-dopa at enzymatic oxidation of dopa in the presence of ascorbic acid. Acta Dermatovener. (Stockholm), 61, 147-148.

Ingraham, L.L., Corse, J. \& Makower, B. (1952) Enzymatic browning of fruits. III. Kinetics of the reaction inactivation of polyphenoloxidase. J. Amer. Chem. Soc., 74, 2623-2626.

Lerch, K. (1983) Neurospora tyrosinase: structural, spectroscopic and catalytic properties. Mol. Cell. Biochem., 52, 125-138.

Mason, H.S. (1955) Comparative biochemistry of the phenolase complex. In: Advances in Enzymology, vol. 16, edited by F.F. Nord, Interscience Publishers Inc., New York, pp. 105-184.

Matoba, Y., Kumagai, T., Yamamoto, A., Yoshitsu, H. \& Sugiyama, M. (2006) Crystallographic evidence that dinuclear copper center of tyrosinase is flexible during catalysis. J. Biol. Chem., 281, 8981-9003.

Miranda, M. \& Botti, D. (1983) Harding-Passey mouse melanoma tyrosinase inactivation by reaction products and activation by L-epinephrine. Gen. Pharmacol., 14, 231-237.

Nelson, J.M. \& Dawson, C.R. (1944) Tyrosinase. In: Advances in Enzymology, vol. 4, edited by F.F. Nord, C.H. Werkman, Interscience Publishers Inc., New York, pp. 99-152.

Salkowski, H. (1884) Ueber die isomeren oxyphenylessigsäuren. Chem. Ber., 17, 504-510.

Seiji, M., Sasaki, M. \& Tomita, Y. (1978) Nature of tyrosinase inactivation in melanosomes. Tohoku J. Exp. Med., 125, 233-245.

Spritz, R.A., Ho, L., Furumara, M. \& Hearing, V.J. (1997) Mutational analysis of copper binding by human tyrosinase. J. Invest. Dermatol., 109, 207-212.

Tomita, Y. \& Seiji, M. (1977) Inactivation mechanism of tyrosinase in mouse melanoma. J. Dermatol., 4, 245-249.

Tomita, Y., Hariu, A., Mizuno, C. \& Seiji, M. (1980) Inactivation of tyrosinase by dopa. J. Invest. Dermatol., 75, 379-382.

Tudela, J., Garcia-Canovas, F., Varon R. Jimenez, M., GarciaCarmona, F. \& Lozano, J.A. (1988) Kinetic study in the transient phase of the suicide inactivation of frog epidermis tyrosinase. Biophys. Chem., 30, 303-310.

Van Gastel, M., Bubacco, L., Groenen, E.J.J., Vijgenboom, E. \& Canters, G.W. (2000) EPR study of the dinuclear active copper site of tyrosinase from Streptomyces antibioticus. FEBS Letters, 474, 228-232.

Waley, S.G. (1985) Kinetics of suicide substrates: Practical procedures for determining parameters. Biochem. J., 227, 843-849.

Walsh, C.T. (1984) Suicide substrates, mechanism-based enzyme inactivators: Recent developments. Ann. Rev. Biochem., 53, 493-535.

Wood, B.J.B. \& Ingraham, L.L. (1965) Labelled tyrosinase from labelled substrate. Nature, 205, 291-292. 